\title{
Hybrid-dynamic objects: DGS environments and conceptual transformations
}

\author{
Stavroula Patsiomitou \\ Visiting Lecturer (University of Crete), PhD (University of loannina), MEd (National and Kapodistrian University of Athens), Greece \\ E-mail: spatsiom@gmail.com \\ ${ }^{*}$ Corresponding Author
}

How to Cite: Patsiomitou, S. (2019). Hybrid-dynamic objecs: DGS Environments and Conceptual Transformations. International Journal for Educational and Vocational Studies, 1(1), 31-46. DOI: https://doi.org/10.29103/ijevs.v1i1.1416

\section{ARTICLE HISTORY}

Received: 5 April 2019

Revised: 10 April 2019

Accepted: 14 April 2019

\section{KEYWORDS}

Dynamic Geometry Software

hybrid-dynamic object

APOS theory

procept-in-action

\section{ABSTRACT}

A few theoretical perspectives have been taken under consideration the meaning of an object as the result of a process in mathematical thinking. Building on their work, I shall investigate the meaning of 'object' in a dynamic geometry environment. Using the recently introduced notions of dynamic-hybrid objects, diagrams and sections which complement our understanding of geometric processes and concepts as we perform actions in the dynamic software, I shall explain what could be considered to be a 'procept-in-action'. Finally, a few examples will be analyzed through the lenses of hybrid and dynamic objects in terms of how I designed them. A few snapshots of the research process will be presented to reinforce the theoretical considerations. My aim is to contribute to the field of the Didactics of Mathematics using ICT in relation to students' cognitive development.

This is an open access article under the CC-BY-SA license.

\section{Introduction}

When a student endeavors to interpret the word "object", s/he could consider it through different lenses: as something material we can perceive through our sensory system, as something that we can act on, or/and as something we can think about. Mathematical objects are a particular kind of object (e.g., functions, operations on functions, spaces of all kinds-for example Banach spaces, geometrical figures).

Numerous researchers have investigated the nature of mathematical objects and tried to define them (e.g., Davis, 1983, 1984; Piaget, 1985; Gray \& Tall, 1991, 1994; Dubinsky, 1991; Dubinsky \& McDonald, 2001; Sfard, 1987, 1989, 1991, 1992; Tall et al., 2000). As we know, since Plato, a mathematical object has been considered as something abstract. Portnoy et al. (2006) report Plato's (360 B.C.) perspective on the figural constructions of geometers as a connection between the figural objects (perceived objects) and the corresponding conceptual objects (conceived objects):

"they are not thinking about these figures but of those things which the figures represent; thus it is the square in itself and the diameter in itself which are the matter of their arguments, not that which they draw; similarly, when they model or draw objects, which may themselves have images in shadows or in water, they use them in turn as images, endeavoring to see those absolute objects which cannot be seen otherwise than by thought. (Plato's Republic, 360 B.C., p. 391, reported in Portnoy et al., 2006, p. 199).

Building on the aforementioned researchers' viewpoint, one might wonder: Are the students able to grasp logical operations on abstract mathematical objects? What does it mean to obtain access to an abstract mathematical object or a mathematical entity? This assumption imposes a series of questions about the nature of the mathematical objects to which symbols are presumed to refer; for example, if we are not able to have access to mathematical objects, which processes could become mental objects whose aim is to reinforce students' cognitive development in mathematical thinking?

In the current paper, I am going to present a theoretical frame based on empirical results consisted of the following parts: (a) mathematical objects, and operations on mathematical objects and their representations (b) the meaning of object in Action-Process-Object-Schema (APOS) theory (c) the notion of procept [-in-action] in a Dynamic Geometry System (DGS) (d) dynamic objects and hybrid objects in a DGS environment, and (e) an analysis of examples of procepts-in-actions that occurred during my research process in a DGS. My aim is to contribute to the 
field of the didactics of mathematics in relation to students' cognitive development.

\section{What is a mathematical object?}

A large amount of researchers pointed out that a mathematical object can be represented using different models and representations (e.g., Chevallard, 1989; Janvier 1987) or semiotic systems (e.g., Duval, 1993, 1995, 1999, 2000). As Duval (1993) argues "[...] on the one hand, the learning of mathematical objects cannot be other than a conceptual learning and, on the other hand, it is only by means of semiotic representations that an activity on mathematical objects becomes possible" (p. 38). Moreover, according to Duval (1999) "the only way of gaining access to mathematical objects is using signs, words or symbols, expressions or drawings"(p.60).

On the other hand, what is a mathematical concept? In the words of Peirce (1894): "We think only in signs. These mental signs are of mixed nature; the symbol-parts of them are called concepts [...]" (Peirce, 1894, reported in Stewart, 2008 , p. 12). In order to develop an understanding of a concept, the students have to create a transitional bridge between the 'external' and the 'internal or mental' representation of this concept (e.g, Kaput, 1999; Goldin \& Shteingold, 2001; Pape \& Tchoshanov, 2001; Tchoshanov, 2013). Tchoshanov (2013) also argues that "the development of students' representational thinking is a two-sided process, an interaction of internalization of external representations and externalization of mental images" (p. 74).

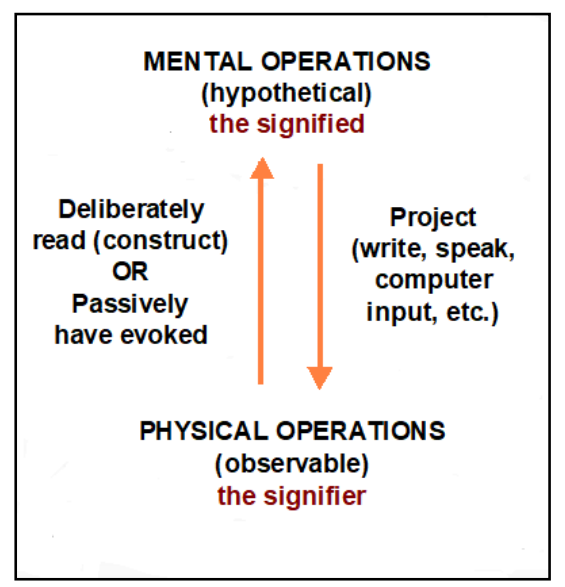

Figure 1. The relation between mental representations and physically instantiated representations (Kaput, 1991, p. 57): an adaptation for the current study

Moreover, students' visualization of an object may differ from their perception of it, while the important thing is to understand which mathematical concept or relationship is being represented. A computer microworld such as a DGS is an external representational system that can encourage students to interact with visually represented mathematical concepts and ideas and can help them to translate between mathematical representations or interpret information received from a real world environment. Kaput (1991) reporting Vergnaud (1987) explains and depicts the relation between mental representations (i.e. the signified) and material represen-tations or physically instantiated symbols (i.e. the signifier), for example pictorial, diagrammatic notations, mathematical symbols, diagrams, graphic representations. According to Kaput (1991).

"When using such material notations, we build and/or elaborate our mental structures in cyclical processes that go in opposite directions. The arrow pointing upward is intended to depict two types of processes: deliberate reading, and the more passive, less consciously controlled and less serially organized processes of having mental phenomena evoked by the physical symbols."(p. 57)[...] The directionality of the reference depends on the cognitive operations involved, which in turn depend on the context, and hence is not fixed".(p.59).

Kaput (1991) also clarifies Peirce's (1933) semiotic behavior as involving an interaction among "sign, object and interpretant", giving an example: "a numeral A-the sign, that refers to the numerosity of a set of objects B-the object and the mind in which the integration takes place-the interpretant [...]" (p.59). For Peirce a sign is "anything which on the one hand is so determined by an object and on the other hand so determines an idea in a person's mind [...] the interpretant of the sign, is thereby mediately determined by that object. [...] " (Hoffmann, 2004, p. 198). According to Adda (1984).

"First of all, being abstract, the objects of mathematics that are treated, the properties and the relations that are studied can never be seen (in contrast, for example, with the objects studied by the physical and natural sciences) and so the distance between the signified and the signifiers plays here a role that is more crucial than for any other type of discourse. [...] By studying the "misunderstandings" brought about by this confusion between signifier and signified we have observed the responsibility they bear not only in a very great number of errors but also in the impossibility of acquiring the concepts themselves" (p.58).

Many researchers (e.g. Dienes, 1960; Piaget, 1972 a, b; Davis, 1983, 1984) also, "focused on the idea of a process becoming a mental object [...] as a fundamental method of cognitive development in mathematical thinking" (Davis, Tall \& Thomas, 1997, p.132). On the other hand, in the words of Sfard (1989) "How can anything be a process and an object at the same time?" (Sfard, 1989, reported in Gray\& Tall, 1991, p. 72).

Gray \& Tall (1991) define the meaning of 'procept' as a combination of the words "pro-[cess] + [con]-cept", "to be the amalgam of process and concept in which process and product is represented by the same symbolism" (Gray \&Tall, 1991, p. 73). A procept, "is consisted of a collection of elementary procepts which have the same object" (Gray \& Tall, 1994 reported in Davis, Tall \& Thomas, 1997, p.134). The meaning of an elementary procept is according to them "an amalgam of [...]: a process which produces a mathematical object and a symbol which is used to 
represent either process or object [...]" (Gray \& Tall, 1994 reported in Davis, Tall \& Thomas, 1997, p.134). Sfard (1989, 1991, 1992) also identifies that a mathematical object, or an abstract object generally, can be conceived or interpreted both operationally, when it is considered as a performed process or a process to be carried out, and structurally when it is interpreted as a permanent object with concrete properties. She identifies the meaning of reification as the next step in the mind of learner as "it converts the already condensed process into an object-like entity" (Sfard, 1992, pp. 64-65, in Davis, Tall \& Thomas, 1997, p.133). In Sfard's opinion mathematical objects can be seen as discursive objects within a mathematical discourse occurred or taking place in a classroom.

A brief survey of the literature reveals that many researchers have generally used the terms 'abstract object', 'process', 'procept', to describe phenomena observed in the areas of Algebra and Calculus. But can these meanings be implemented in the mathematical area of Euclidean or Dynamic geometry?

\section{Operations on mathematical objects and their representations}

For most researchers, representations can help students to reorganize and translate their ideas using symbols. They are also useful as communication tools (e.g., Kaput, 1991) and can function as tools for understanding of mathematical objects and concepts, since they help with the communication of ideas and provide a social environment for the development of mathematical discussion. The knowledge of supporting external representational systems for planning activities, allows us to facilitate the provision of information and support conceptual understanding of mathematical objects and the development of their representational thinking. Students face difficulties when they explore mathematical objects, no matter if they are in a static or dynamic environment. They have to mentally operate on the abstract object, even if it is visually supported by a computing environment. This is what Laborde (2003) investigates, interrogates or (probably) asks herself: "but if the thought experiments on abstract objects are not available (as it is often the case for learners), a crucial question about learning is whether such environments could favour an internalization process of the external actions in the environment". The concept of a function, for example, is a mathematical object that cannot be smoothly understood by high school students, especially by students who find maths difficult. I shall mention a path regarding the concept of function based on my experience as a teacher of mathematics which can scaffold students and allow them to gradually grasp all the more abstract mathematical objects.

Elementary level arithmetic and algebraic approach: "1 $\mathrm{kg}$ of apples costs 2 Euros, $2 \mathrm{~kg}$ cost 4 Euros [...] x kg cost y Euros. What is the relationship between $\mathrm{x}$ and $\mathrm{y}$ ?" The appearance of the variables $\mathrm{x}$ and $\mathrm{y}$ reveals a limited understanding on the part of students because $\mathrm{x}$ and $\mathrm{y}$ are symbols used as signifiers referring to objects; in the words of Piaget (1952/1977), they are "intentionally chosen to designate a class of actions or objects." (p.191). The question is how the relationship between different kinds of objects can be shown? Which procedure/or procedures can we apply so that the concept of function is easily understandable for students? Do these procedures or processes lead to an understanding of the concept of function?

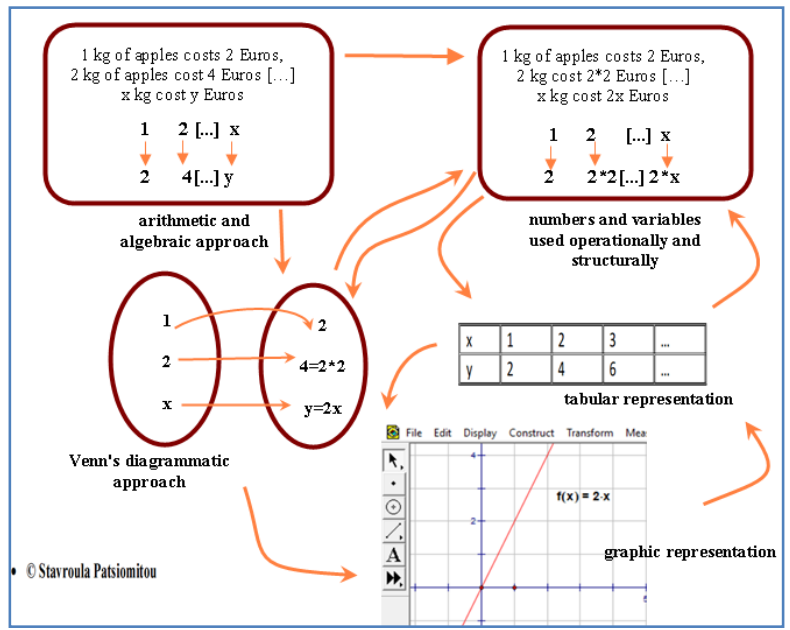

Figure 2. Linking the different kinds of representation of a function

1st level. The variable's approach: I continue: $1 \mathrm{~kg}$ of apples costs 2 Euros, $2 \mathrm{~kg}$ costs $2 * 2$ Euros etc.; [...] the number 6 is represented/signified by the product $2^{*} 3$ and the symbol $\mathrm{y}$ is represented/signified by the product $2 * \mathrm{x}$. (i.e., $\mathrm{x} \mathrm{kg}$ cost $2 \mathrm{x}$ Euros). The expression $2 * 3$ is the same notation to represent both a process and the product of that process. In other words it "could be used both operationally, as denoting an operation, and structurally, as signifying an object (the result of an operation). The fact, however, that the same signifier had to be employed in two seemingly incompatible roles, operational and structural, certainly aggravated the difficulty of reification" (Sfard, 2000, p.50).

2nd level. A diagrammatic approach: The next step is the construction of Venn diagrams in which arrows connect the A set of numbers representing kilograms with the B set of numbers representing Euros. When representing objects in Venn diagrams, we use dots for objects. Constructing Venn diagrams allows students to think about the classification of objects, while the arrows help them to describe relations between objects and understand meanings such as "one to one" and "onto".

3rd level. A graphic and tabular approach: A function is used to describe the expressed relationships between variables. Replacing the numbers $1,2,3 \ldots$ that represent the kilograms with the variable " $\mathrm{x}$ " and constructing a function $(y=2 x)$ in which we determine a rule for a sequence of objects, ultimately provides us with a definition of the concept of function and its graph. Thus, in response to the symbol of the function $\mathrm{y}=2 \mathrm{x}$ ('representamen' in the words of Peirce, 1955) one can draw a line which would be the interpretant of the symbol $\mathrm{y}=2 \mathrm{x}$. 


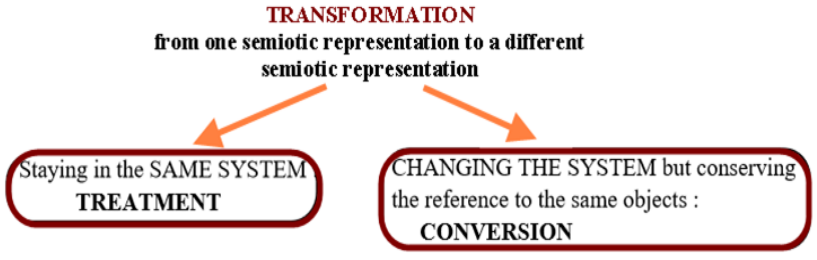

Figure 3. Types of transformations of semiotic representations (Duval, 2002, p.3): an adaptation for the current study

The prerequisite here for students is a structural knowledge of numbers which allows them to use numbers to build a more complex concept. In Figure 2, we can view both treatments and conversions between the aforementioned semiotic representations.

- "Treatments are transformations of representations which happen within the same register [...] (Duval, 2002, p.3)

- Conversions are transformations of representation which consist of changing a register without changing the objects being denoted [...]" (Duval, 2002, p.4).
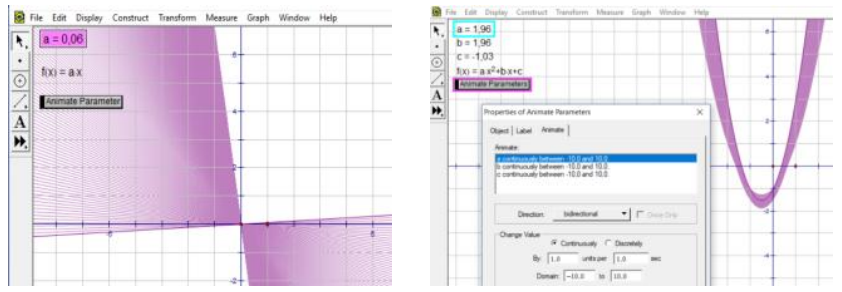

Figure 4a, b. Snapshots of families of functions using the animation of parameters

If we use a parameter "a" to define a function $y=a x$ and represent it in a Dynamic Geometry System (DGS), the family of representations we take as we animate the parameter could result in the perception of an empirical generalization of the concept of function. The traces of the object $y=a x$ as we animate the parameter "a" provide the path through which the function is transformed (Fig. 4a, b). Then we can transform the parameter, but the result of the parameter's alterations affects the linked graphic representations, providing a family of objects with the same properties, which can help students, achieve a deeper understanding.

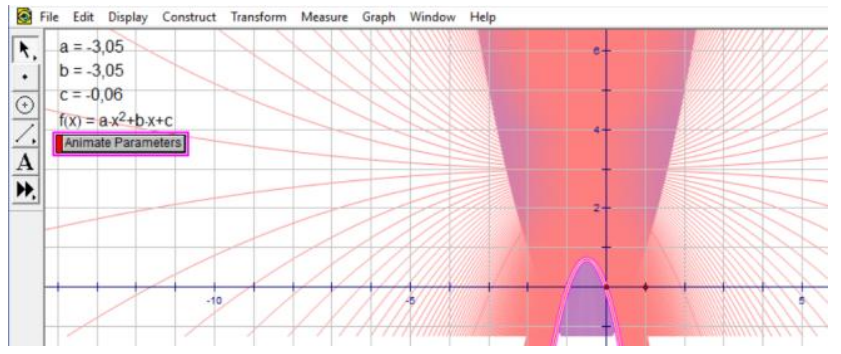

Figure 4c: Snapshots of families of functions using the animation of parameters (e.g., Patsiomitou, 2009b)

These traces are not a static mathematical object. They are not dynamics, as they cannot be dragged, but neither are they static. So what kind of object are the lines the traces leave on screen? I have denoted them as hybrid objects (Patsiomitou, 2019, p. 15).
Traces play an important role in helping students understand the transformations of parameters and their impact on the graphic representations.

Similarly, transformations in geometry are mentioned by many researchers as 'geometric functions' (e.g., Hollebrands, 2003, p.57; Steketee \& Scherr, 2016, p.450; Patsiomitou, 2006c, p.1072, 2019). Hollebrands (2003) defined transformations as follows:

"Transformations are special functions because they are both one-to-one and onto. Understanding that a transformation is one-to-one involves knowing that if you have two different elements in the domain (two points $A$ and $B$ such that $A \neq B$ ) then the output for $A$ under the transformation will be different from the output of $B$ under that same transformation $(T(A) \neq T(B)$ where $T$ represents a transformation). Understanding that a transformation is onto involves knowing that every element in the range (every point $Q$ in the plane) has a corresponding element in the domain (a point $P$ in the plane) such that $T(P)=Q$ ”. (p. 57)

Steketee \& Scherr (2016) also report dependent and independent variables, denoting the geometric transformations of objects in a DGS as "geometric functions" and arguing that:

"Cognitive scientists tell us that students build abstract mathematical concepts by connecting those concepts to the physical world through conceptual metaphors (Lakoff and Núñez 2000; Radford 2012), such as the metaphor that numbers are points on a line. Geometric functions are based on a similar metaphor-that geometric variables are movable points. [...] This metaphor enables students to use dynamic software to create a point (the independent variable), construct another point (the dependent variable) that depends on the first, and drag to observe the resulting covariation and relative rate of change. In other words, a geometric function relates the preimage point-the independent variable $x$-with its image-the dependent variable that is a function of $x . "(p .450)$

The difficulty of students to imagine transformations on geometric figures during problem solving situations is based in the nature of geometrical concepts which Fischbein (1993) defined as an amalgam of: "abstract ideas on one hand and sensory representations reflecting some concrete operations on the other" (p. 140). Duval (1999) in his plenary paper, "Representation, vision and visualization: cognitive functions in mathematical thinking. Basic issues for learning", describes three kinds of operations delimited by how a given figure is transformed:

“(a) The mereologic way: you can divide the whole given figure into parts of various shapes [...] and you can combine these parts in another whole figure or you can make appear new subfigures.[...]. We call "reconfiguration" the most typical operation.

(b) The optic way: you can make a shape larger or narrower, or slant, as if you would use lenses. In this way, without any change, the shapes can appear 


\section{differently [...].}

(c) The place way: you can change its orientation in the picture plane. It is the weakest change. It affects mainly the recognition of right angles, which visually are made up of vertical and horizontal lines" (Duval, 1988, pp. 61-63; 1995, p.147).

The mereologic, the optic way and the place way constitute what Duval defined as "the operative apprehension" of the figure, which according to him differs from the perceptual apprehension "because perception fixes at the first glance the vision of some shapes and this evidence makes them steady"(p.19) [...] Operative apprehension is [also] independent of discursive apprehension"(p.21).

Thus, we have to act or operate on external objects or on external representations of these objects or on their external symbols. This is in accordance with what Piaget (1970) stated about mathematical knowledge which can be abstracted either directly from objects or the external experiences we have in relation to the objects, or from operations that are mentally performed on objects.

\section{Dynamic objects and dynamic hybrid objects in a DGS environment}

Dynamic mathematical objects are a particular kind of mathematical objects, created in a dynamic geometry software (DGS). Generally speaking, microworlds have been created to support abstract thinking through visual representations on computer screen and their transformations. Laborde (2003) in her article "Technology used as a tool for mediating knowledge in the teaching of mathematics: the case of Cabri-geometry" stated that:

"the idea of computer environments as reifying abstract objects and structures originates from the notion of microworld in which it is possible to explore and experiment on representations of abstract objects as if they were material objects" (p.6)

Dynamic Computer software programs, such as the Geometer's Sketchpad (Jackiw, 1991/2001), Cabri II (Laborde et al., 1988), Geogebra (Hohenwarter, 2001) etc. are means with which students are able to create mathematical objects, using tools and commands. Dynamic geometry environments are defined by Balachef \& Kaput (1997) as :

“( $a$ ) a set of primitive objects (point, line, segment, circle, etc.) created by the tools of the software and (b) of elementary actions (for example, commands to draw a perpendicular or a parallel line given a point and a line etc.). (p.8)

We can also create a macro construction or a custom tool which "allows an organized set of primitive actions to be turned into a complex one" (Balachef \& Kaput, 1997, p. 12).

In the case of algebraic patterns, mathematical objects can be represented and illustrated in both numerical and figurative modes as a way of generalizing them.

\begin{tabular}{|lcccccc|c|}
\hline 1 & 2 & 3 & $\ldots$ & $n \cdot 2$ & $n \cdot 1$ & $n$ \\
$n$ & $n-1$ & $n-2$ & $\ldots$ & 3 & 2 & 1
\end{tabular}

Kaput (1991) for example revisits the problem that Gauss phased to sum the integers from 1 to 100 , "exploiting a convention for expressing generality in mixed numerical and algebraic notation" (p.68). Kaput mentions a "hybrid sum" (numeric and algebraic) which is illustrated using the powerful mode of another "hybrid sum" (figurative and symbolic).

Many researchers use the word "hybrid" to denote something that does not obviously belong in a given class of objects, or a mixed entity composed of different elements. Verillon \& Andreucci (2006) for example in their study "Artefacts and cognitive development:how do psychogenetic theories of intelligence help in understanding the influence of technical environments on the development of thought?" report Rabardel (1995) who argued that during instrumental genesis "the resulted instruments are actually hybrid entities, on the one part are psychological and on the other part artefactual" (p.12). Morgan et al. also mention the representational hybrid nature of the Turtleworlds environment, because it behaves like a hybrid between Logo and Dynamic Manipulation systems due to the 'variation tool' (Morgan et al. https://www.itd.cnr.it/telma/docs/Rep_Del_Draft3.pdf, p.7). Cerulli (2004) also mention "a hybrid language to be used to bridge the natural language with the mathematical one" (p.36). As Cerulli states "the evolution of meanings is based on the idea of deriving, from a used instrument, hybrid signs which refer both to the practice with the instrument and to the sphere of theory of mathematical knowledge" (p. 142). Firstly, speaking of a DGS environment, it is important to identify the meanings of geometrical objects in such an environment (Patsiomitou, 2019, pp. 14-15).

- I will use the meaning of dynamic geometrical object, to denote every object that has been constructed in a dynamic geometry software interface. This object could be a "drawing" or a "figure" which intrinsically has dynamic properties. Gonzalez and Herbst (2009) have defined the dynamic diagram as "a diagram made with DGS and that has the potential to be changed in some way by dragging one or more of its parts" (p.154).

- I will use the meaning of dynamic diagram, to denote an external representation composed out of a set of rationally related dynamic objects in a DGS environment. A dynamic diagram can be a simulation of a problem modeled in the DGS environment, which 
includes many geometric objects and combinations of interaction techniques implemented in these objects.

- I introduced the meaning of dynamic section (Patsiomitou, 2019, p. 15) to denote a set of dynamic diagrams that are linked to each other procedurally and conceptually, even if they differ structurally. A dynamic section contains meanings belonging to the same class that are united or joined into a whole, which in the concrete situation symbolically means they exist in one [alive book] section or they are dynamically linked. As I have written in a previous work (Patsiomitou, 2018b, p.40):

\section{“A first and very important effect on students' thinking stems from the Sketchpad software allowing the user to create sequential linking pages so that the whole Sketchpad file becomes an "alive book" (Patsiomitou, 2005, p. 63, in Greek; Patsiomitou, 2014). The "alive digital representations" (Patsiomitou, 2005, p. 67) function, which makes the whole figural diagram "alive", giving the students the potential to focus their attention on simultaneous modifications (and transformations) of objects on the screen (Patsiomitou, 2005, p. 68), also yielded important results during my investigations".}

In the Geometer's Sketchpad environment (or the Web Sketchpad) anyone can create a dynamic section by linking pages in the same file. In this way, a solution to a problem can be separated into sequential componential steps that help a student to create linking mental representations in his/her mind (Patsiomitou, 2008b, c, d, 2009 a, b, 2010, 2011, 2012a, b, 2013, 2014, 2018a, b, 2019).

- I introduced the meaning of hybrid object (Patsiomitou, 2019 , p. 15) to denote an on-screen geometric object that is intrinsically dynamic but remains untransformed /unaltered on screen, even though dynamic dragging is applied or implemented on it. This situation comes about because of the hybrid object's dependence from its parent objects. Briefly, a hybrid dynamic object is something that does not obviously belong to either the static or dynamic world. It is an object created in a DGS by means of complex transformations (or on which complex transformations can be performed); something between a static and a dynamic object; an object that is intrinsically dynamic, signifying a static behavior which is rendered dynamic by to the users' actions.

- I introduced the meaning of hybrid diagram (Patsiomitou, 2019, p. 15) in the DGS environment to denote the untransformed on-screen diagram, which has been created to stay hybrid and become dynamic if we implement a transformation on its parents. The diagram is intrinsically dynamic, but a user could use it as an image or a static diagram, if $\mathrm{s} / \mathrm{he}$ does not know how to make it dynamic. It is important to point out at this point that: the transformation of objects in a DGS environment is dependent on whether these objects have been defined, as hybrid objects or not.

\section{The implementation of APOS theory in a DGS environment}

One way to analyzing students' formulations during their interaction with dynamic geometry transformations on dynamic or hybrid objects is to consider those formulations through the Action-Process-Object-Schema (APOS) theory lenses, a theory developed from Dubinsky and his colleagues (e.g., Dubinsky, 1988, 1991; Dubinsky \& McDonald, 2001), based on the theory of reflective abstraction (Piaget, 1970). Concretely, according to APOS theory (Cottrill et al., 1996; Dubinsky \& McDonald, 2001) when a student constructs mental Actions, Processes and Objects, then s/he organizes them to mental Schemas to understand a mathematical concept and solve the problems (APOS theory). According to APOS theory, in order to understand a mathematical concept a student must manipulate physically or mentally a transformation on mental or physical objects, in other words an "Action" on objects, as a reaction to stimuli perceived from the external environment, focusing on the way that a procedure thus could be used as an input to another procedure; actions on objects then can be interiorized to become a Process, which accordingly can be encapsulated to become Objects and then can be organized to become Schemas. According to Cottrill et al. (1996):

An action is any physical or mental transformation of objects to obtain other objects. It occurs as a reaction to stimuli which the individual perceives as external. It may be a single step response, such as a physical reflex, or an act of recalling some fact from memory. It may also be a multi-step response, by then it has the characteristic that at each step, the next step is triggered by what has come before, [authors italics...] When the individual reflects upon an action, he or she may begin to establish conscious control over it. We would then say that the action is interiorized, and it becomes a process (Cottrill, et al, 1996, p. 171, in Davis, Tall and Thomas, 1997, $p$. 133).

Making a review on the briefly reported studies it is obvious that many researchers have mentioned the meanings of Action-Object-Process-Schema, to describe the phenomena observed in the area of Algebra and Calculus. Can these meanings be implemented in the mathematical area of Euclidean or Dynamic geometry? What is their impact in the reification process? As Balacheff \& Kaput (1997) point out their impact "is based in a reification of mathematical objects and relations that students can use to act more directly on these objects [...] a new experiential mathematical realism" (Balacheff \& Kaput, 1997, p. 469-470).

Hollebrands (2003) investigated the nature of students' understandings of geometric transformations in the context of "The Geometer's Sketchpad" environment and she analyzed students' conceptions of transformations as functions, using APOS theory. Hollebrands (2007) also addressed the way students interpret objects created with the use of the dynamic program when they are learning about geometric transformations. As Hollebrands argued "the nature of the abstractions that students made as they worked with technology seemed to be related to their understanding of transformations and the tool" (2007, p. 190).

Patsiomitou (2019) also reports that she instrumentally 
decoded Vecten's theorem using dynamic parameters (Patsiomitou, 2006c, in Greek, p. 1272):

"The animation of all parameters is a direct object manipulation which transforms every part of the object. This leads to a kind of algebraic geometry, which takes the parametric sides and angles as input and provides a continuous transformation of the diagram as output [...] we can thus speak about functional geometry and through the conservation of figures' properties about the concept of geometric function".

During the synthesis of a dynamic diagram in a DGS environment a student manipulate the dynamic primitives and transforms the diagram. S/he interacts with the diagram and creates mental objects that can be encapsulated to become a mental schema. The way that the students use the tools in a DGS environment follows the "rules" for the tools that have been addressed by Verillon \& Rabardel (1995) during instrumental genesis process:

"A machine or technical system does not immediately constitute a tool for the subject. Even explicitly constructed as a tool, it is not, as such, an instrument for the subject. It becomes so when the subject has been able to appropriate it for himself-has been able to subordinate it as a means to his ends-and, in this respect, has integrated it with his activity" (pp. 84-85).

Instrumental genesis is a process during which an artefact with which the student interacts, becomes an instrument (Drijvers, \& Gravemeijer, 2005 ; Drijvers, \& Trouche, 2008). Cerulli (2004) clarifies the difference between the meaning of artifact and the meaning of instrument in her thesis. As she states:

"An instrument, for us, is a means used, on purpose, by an agent in order to achieve an objective, the agent (will usually be considered to be human). It can be anything, or any object, depending on what it is used for and how.

Thus, we have either instruments that are artefacts, or instruments that are not artefacts; for instance, a hammer, or a stone, can be used as instruments to drive in nails, but the first one is an artefact, whilst the second is not, it is simply an object" (Cerulli, 2004, p.8).

During instrumental genesis the learner builds utilization schemes and instrumented action schemes in "the two-sided relationship between tool and learner as a process in which the tool [...] shapes the thinking of the learner, but also is shaped by his thinking" (Drijvers \& Gravemeijer, 2005, p. 190). The notion of 'scheme' is central to Piaget's theory, while Vergnaud (1998) gives a more dynamic interpretation of the notion. According to Vergnaud (1998) "the concept of a 'scheme', is the invariant organization of behavior for a certain class of situations. [...] The theorems-in-action and concepts-in-action are operational invariants and, as such, essential components of schemes" (p.167). From Trouche's point of view, (personal e-mail correspondence with Professor Trouche on October $22,2007)$ " $[. .$.$] what is important is to analyze the$ operational invariants [... meaning "the concepts-in-actions, that is concepts that are implicitly considered as pertinent, or theorems-in-actions that are propositions believed to be true" (Trouche, 2004, p. 285).

Generally speaking, when we solve a problem in geometry, we construct a figure in a few steps and in such a way that a procedure can be used as an input to the next--and almost always sequential--procedure. As they engage in problem solving, students construct mental actions, performing transformations on objects either explicitly or from memory. The student or the teacher can perform an operation mentally and execute it on the computer screen. This process creates objects.

For example, in order to draw a circle with centre A and radius $\mathrm{AB}$, a student constructs a utilization scheme of the DGS tool. When s/he repeats the process to construct a congruent circle with centre $\mathrm{C}$ and radius $\mathrm{CD}=\mathrm{AB}$ s/he is focused on the way in which the new procedure resulted as an output from a few previous procedures (for example the usage of software primitives). This is a process for creating a congruent circle, which can be encapsulated to become a mental object. At the same time, the student has constructed an instrumented action scheme, which enables him/her to connect meanings (for example the meaning of congruent circles with the meaning of congruent radiuses). A segment (or a line) in the Euclidean geometry is a geometrical object. We can create segments in a DGS environment, then measure their length and calculate their sum. We can also use the symbol "+" to represent the process of segments' addition, leading to the concept of segments' sum in geometry, in a similar way that Davis et al. (1997, p.134) report its pivotal role in algebra. Concretely, Davis et al. mention that

"The symbol 4+2 occupies a pivotal role, as the process of addition (by a variety of procedures) and as the concept of sum. Soon the cognitive structure grows to encompass the fact that 4+2, 2+4, 3+3, 2 times 3, are all essentially the same mental object" (Davis et al., 1997, p.134).

Building on the above, I think there is a continuous process ongoing in students' mind as they create a concept. The meaning of 'procept' is thus dynamic in a DGS environment; adapting its meaning to a 'procept-in-action' for the DGS environment could thus support the appearance of operational invariants during the problem-solving situation and the students' actions on a dynamic object or a dynamic representation/diagram.

\section{The addition and sum of two segments in a DGS environment}

Secondary students in Greece study the axiomatic foundation of Euclidean geometry from the first classes of high school. In terms of Euclid's definitions "a straight line is a line which lies evenly with the points on itself" (Def. 4). Between the fundamental Euclid's definitions they have heard, is the definition of the segment. The definition of a segment $\mathrm{AB}$ given in most Greek geometry textbooks is as follows: "segment $\mathrm{AB}$ is the figure which consists of the endpoints A, B and the set of points which belong to the portion of the line between these two endpoints". The DGS environments have been designed to 
take the Euclidean definitions and propositions into account. I use the term 'dynamic' point to refer to a point made in a DGS. A 'dynamic' point is a fundamental element in a dynamic construction. 'Dynamic' segment is a segment made in a DGS. According to the Geometer's Sketchpad reference manual (2001) "points are the fundamental building blocks of classical geometry, and geometric figures such as lines and circles are defined in terms of points" (p.11). Hollebrands, Laborde \& Straeser (2008, p.165) described the distinction between the three different kinds of points in a DGS environment: (a) a free point "can be directly dragged anywhere in the plane (degree of freedom 2)", (b) a point on an object "can be dragged only on this object (degree of freedom 1)" and (c) a constructed point "cannot be grasped and dragged (degree of freedom 0) but moves only if an element of which it is dependent is dragged". Hollebrands (2007) also mention that "[...] in the context of dragging, certain characteristics change and others remain the same and these behaviors are generally guided by the definition of the geometric object" (p.168). In a previous study I defined the meaning of dynamic segment as follows (Patsiomitou, 2011):

"The 'dynamic' segment is a portion of a straight line which does not consist of points. Dynamic points can be placed independently on the dynamic segment and move free with one degree of freedom on the path to which they belong. This means that a point placed on a segment that intrinsically is designed with two degrees of freedom is transformed to a segment object with one degree of freedom" (p. 365).

All geometrical or algebraic objects in the Geometer's Sketchpad environment operate in "a dependency diagram, a directed acyclic graph" (Jackiw \& Finzer, 1993, p.295): The 'given' objects in a construction are the 'parents' and they are free to move on the screen, in contradiction to dependent objects which are the 'children' of the objects on which they depend in some fashion, that are constrained. According to Sketchpad Help System in the software are available the objects mentioned in the fig. 6, below:

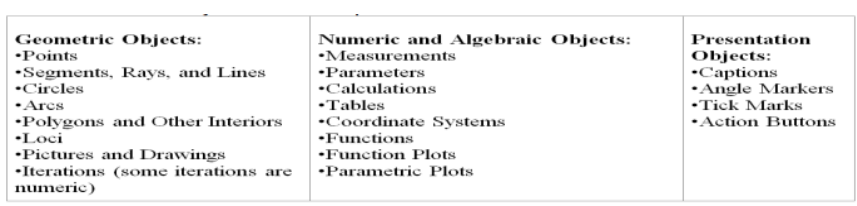

Figure 6. Objects available in Sketchpad

The case of the addition of two segments in geometry represented by two separate objects identified by two letters, one for each edge of each segment (for example segments $\mathrm{AB}, \mathrm{CD}$ ) is more complex, because it includes both a figural and an algebraic entity. The figure of the segment which represents a concrete real "thing" is the figural part; the number which is the measure of the segments' length (or the distance of the endpoints of the segment) represents the algebraic part. In addition, the students have to represent the addition of segments with a concrete segment and then represent this action by means of a symbolic representation--namely, the way these segments are defined by letters (AB, CD etc.).

The symbol "AB+CD" possesses a central role as the process of segment's addition and as the concept of segments' sum. The cognitive structure encloses the same mental objects (e.g. $\mathrm{CD}+\mathrm{AB}=\mathrm{FG}+\mathrm{EF}$ if $\mathrm{FG}=\mathrm{CD}$ and $\mathrm{EF}=\mathrm{AB})$. As a result, the construction, measurement and calculation of segments in a DGS environment differ from the same process in a static environment. Then, we can define an elementary geometrical procept. According to Sketchpad Help System:

"The objects you can create in Sketchpad fit into several general categories. Some of the objects are purely geometric entities-points, lines, rays, segments, circles, arcs, interiors, loci, and some iterations. Other objects are either numeric or algebraic entities-measurements, parameters, coordinate systems, calculations, and functions. And finally, some objects in Sketchpad-captions and action buttons-are primarily used in descriptions, explanations, and presentations".

It is thus clear that the sum of the segments as an object derived from calculations in a DGS environment is an algebraic, geometric and "dynamic" entity. I shall break down the process of adding two segments in the DGS environment into two phases.

Phase A. If we create two segments in the Geometer's Sketchpad and then measure and calculate their sum, the actions on mathematical entities at one level become mathematical objects in their own right at another level (Piaget, 1972a, b).

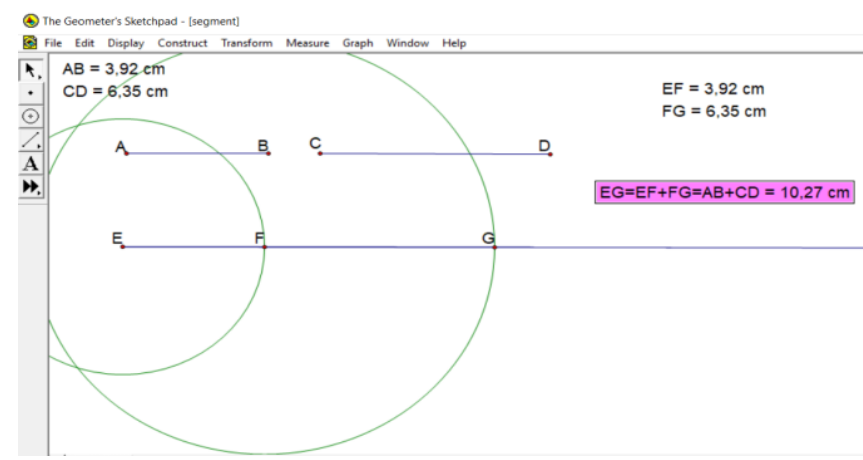

Figure 7. The addition of two segments in a DGS

The calculation of segments is a process becoming reified as an object, which includes a few procedures, in the words of Gray \& Tall $(1991,1994)$ who distinguished between "the specific procedure as an explicit sequence of steps and the input-output process where different procedures can have the same input-output". Selecting the calculation command displays the calculator with which we can sum the segments by selecting the 
measurements of each, as illustrated in Figure 8a below.

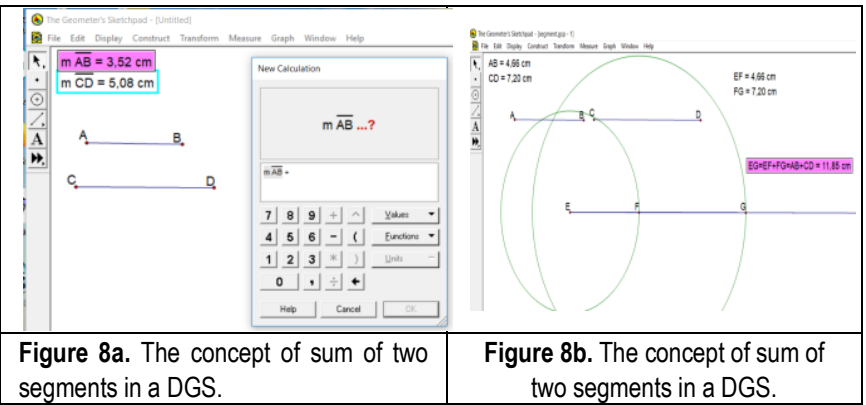

To construct objects in a DGS environment, we can use first-order parental objects, second-order child geometrical objects, and auxiliary objects. I shall try to list in the table below all the actions and symbols involved in the process of adding the segments, the sequence of actions and objects involved. I shall also report the theoretical construct and try to anticipate how students will understand and conceive of the process and the answers they will produce.

The theoretical answers of Euclidean Geometry mentioned in the Table 1 are the following (Coxford \& Usiskin, 1975):

P1: If two distinct points are in a plane, the line determined by these points is a subset of the plane. (p.20)

P2: Two points determine a line. (p. 21)

P3: To each pair of points there corresponds a unique real number called the distance between the points.(p. 22)

P4: Suppose $A$ and $B$ are points, then: (a) $A B \geq 0$, (b) $A B=0$ if and only if $A=B$ and (c) $A B$ is also the distance between $B$ and $A$, that is $A B=B A$. (p. 24)

P5: The segment with endpoints $A$ and $B$ is denoted by $A B$ and is the set whose elements are distinct points $A, B$ and all points between $A$ and B. (p.26)

P6: A line is an infinite set of points (p. 22)

P7: A line is a set of points and contains at least two distinct points. (p. 18)

P8: A circle is the set of all points in a plane at a fixed distance (the radius) from a fixed point (the center). (p.180)

P9: Two radiuses of the same circle are congruent segments.

P10: Congruent radiuses determine congruent circles.

P11: Points $E, F, G$ are collinear since they are all on line Ex. (p.19)

P12: The midpoint of a segment $A B$ is the point $M$ in $A B$ with $A M=M B(p .30)$

P13: The length of a segment is the distance between its endpoints. (p.26)

P14: (Betweenness theorem). If a point $B$ is between $A$ and $C$, then $A B+B C=A C .(p .26)$

P15: (Addition theorem) If $B$ is on $A C$, then $A C=A B+B C$ (p.375)

\begin{tabular}{|c|c|c|c|}
\hline Actions & Objects & $\begin{array}{l}\text { A theoretical view } \\
\text { in Euclidean } \\
\text { Geometry }\end{array}$ & $\begin{array}{l}\text { An anticipation of a student's answer initheration with the } \\
\text { dynamic diggram }\end{array}$ \\
\hline $\begin{array}{l}\text { Conssuction of the } \\
\text { segrents (a procedure } \\
\text { which produces the figurl } \\
\text { parto of the objects). }\end{array}$ & 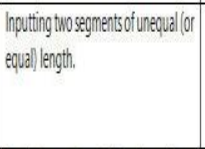 & $\begin{array}{l}\mathrm{P1} \\
\mathrm{P} 2\end{array}$ & 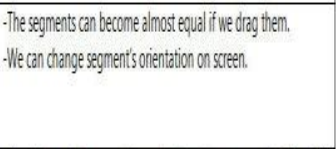 \\
\hline 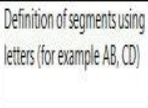 & 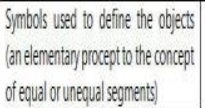 & $\begin{array}{l}P_{3} \\
P 4 \\
P 5\end{array}$ & $\begin{array}{l}\text { The distance between the endopoints of s segmentis saffected if } \\
\text { we orgog them. }\end{array}$ \\
\hline Constuction of a line Ex & $\begin{array}{l}\text { An aviliby geancticial objet (an } \\
\text { elementiay procept) }\end{array}$ & $\begin{array}{l}P 6 \\
P 7\end{array}$ & 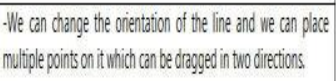 \\
\hline 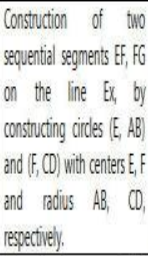 & 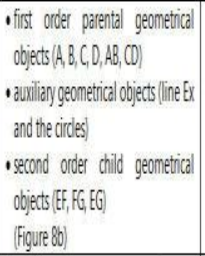 & $\begin{array}{l}\text { P8 } \\
\text { Py } \\
\text { PIO } \\
\text { P11 }\end{array}$ & 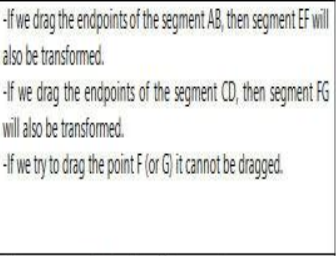 \\
\hline 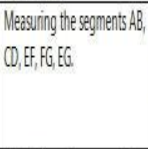 & 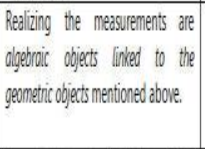 & 912 & 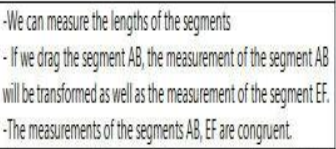 \\
\hline $\begin{array}{l}\text { Calulating the sim of the } \\
\text { segmentisfF, FG. }\end{array}$ & A compler dramic object (Figure eb] & P13 & 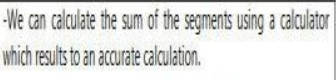 \\
\hline 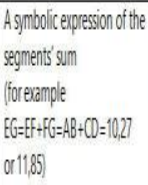 & 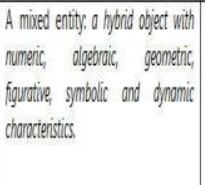 & $\begin{array}{l}\text { P14: Betweenness } \\
\text { theovern }\end{array}$ & 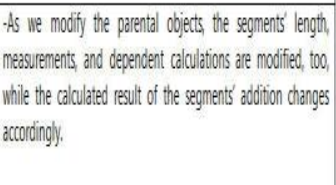 \\
\hline
\end{tabular}

Table 1. Actions and symbols involved in the process of adding the segments

Generally speaking, if we construct a segment using the tools provided by the DGS software, this concrete segment is the parent object and the measurement the child object. In the previous example, points F, G cannot be altered by dragging due to their dependence on their parent objects. Dragging points A, B affects the position of point $\mathrm{F}$ (just as dragging points $\mathrm{C}, \mathrm{D}$ affects the position of point G). Students can understand that "if we modify segment AB, segment EF will be modified also".

In the Table 1 above a description has been done with regard to the objects and the actions. The anticipated answers of students during the interaction with the process lead to the following result: The transformation of all the objects mentioned above, leads the students to conceive the unaltered properties of the mixed entity. They can express a concept-in-action or theorem-in-action, through the reification of mathematical objects and the interiorization of the process of dynamic movement, counting and dragging the segments: this is a procept-in-action, meaning a process which leads to a concept-in-action or theorem-in-action.

Phase B. The mode of constructing a figure in the software (e.g a square of side a) could be different from the mode students use to construct it on paper. For example: When a student works using static means, s/he is able to measure the length of side 'a' with a ruler. Afterwards s/he is able to use this measurement to construct either the next side of the square given that $\mathrm{s} /$ he knows the 
geometrical properties of the shape or of another shape (for example a rectangle) whose one side is equal to ' $a$ '. This "measurement" method is not the method the software demonstrates for constructing a figure which does not mean that the software faces a constructional inability/disadvantage comparing it with static means. By forcing students to think of ways of constructing an equal segment, this methodological weakness can thus provoke a cognitive conflict in students, and in so doing raise the level of difficulty. One such way would be to define side 'a' as an arbitrary segment [i.e., a parameter] on the screen and then use it as a radius of a circle in the construction (Patsiomitou, 2008e, 2009a, b). This construction method inducts a different mental perception in the students with regard to construction in the software. In this way, the sides of the square/or rectangle cannot be modified from the vertices of the figure using the dragging modality. Instead, they depend on the modification of the initially defined segment ' $a$ '. The arbitrary segment 'a' could thus be confined as a non-collapsible compass to either the square or any figure whose a side is equal to 'a'. This construction procedure depends on the students' level of conceptual knowledge and cognitive abilities.

If we create the segments' addition, by defining the segments $\mathrm{AB}, \mathrm{CD}$ using the parameters $\mathrm{a}, \mathrm{b}$ (meaning, by setting a corresponding parameter to each segment, the parameter "a" for the segment $\mathrm{AB}$ and the parameter "b" for the segment $\mathrm{CD}$ ) then we have created concrete invariant objects in a DGS environment. In order to create the parameters we can use the "create a new parameter" command from the Menu, Graph (Figure 9a). According to Sketchpad Help system

"Parameters are simple given numeric values. Unlike measurements and calculations, they do not depend on other objects for their value. A parameter is defined by a single number and an optional unit".

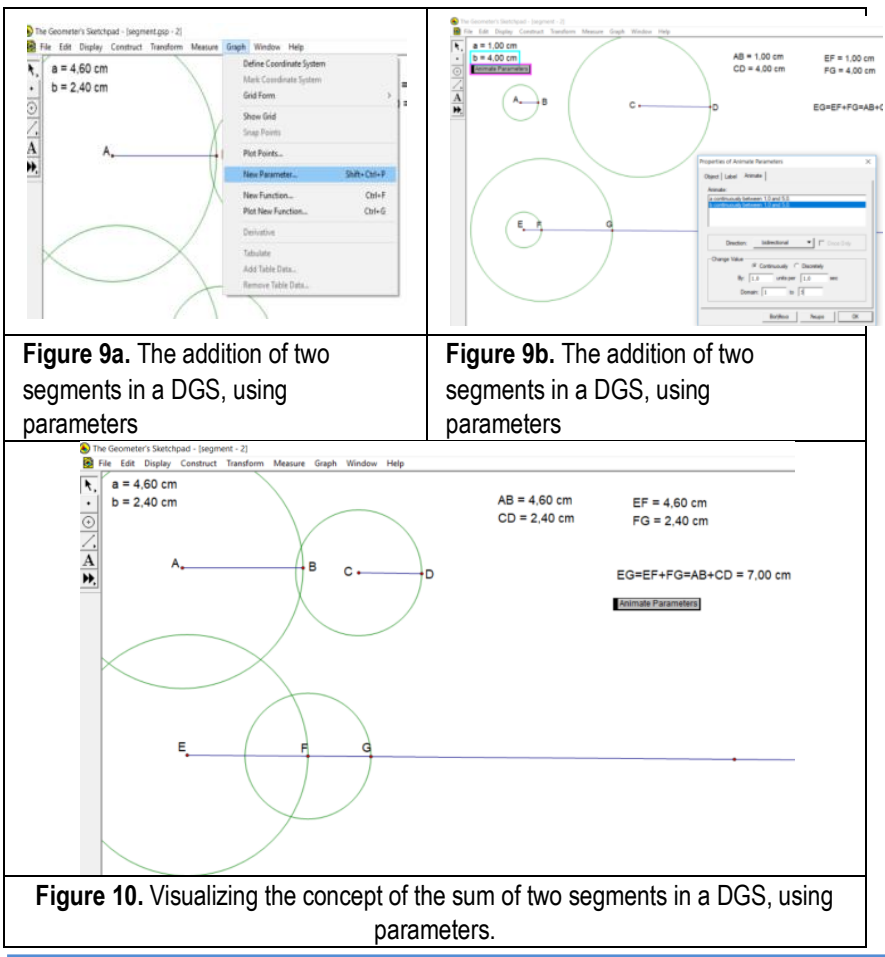

We can choose to construct a segment for example with length equal to $2 \mathrm{~cm}$, or with such a length as we wish. These parametrical segments can be transformed dynamically by transforming (e.g., by using animation) the parameters with which they have been created, meaning the parental objects in a continuous/or not process (Fig. 9b). Firstly, the animation on parameters turns the dynamic diagram to a more detailed and complex representation than the one we have created using the tools (e.g. segments, lines and circles). Points B, D have only one degree of freedom and can be dragged only on the path they belong. The figures can become larger or narrower, but it is not easy to change their orientation (for example, if the circle-path to which they belong becomes hidden). We can change the value of the parameter or define the domain values between which the parameter takes on values (Figure 10), meaning that the geometrical object depends on the values given to an algebraic object. The parameter is allowed to range over whatever domain I choose to define, and the mixed entity has been transformed into a symbolic parametrical and dynamic one (we can see the "animate parameters" label on screen, which allows parameters to be altered with this action affecting the figural part of the object). Secondly, the concept of parameters belongs to algebra. On the other hand, when we create a figure in a static environment, we never use a parameter to create the figure, just as we never define a segment as a parameter for use in our construction. Moreover, animating the parameters transforms the synthesis of the diagram into an "infinite" number of snapshots, which the user would probably not consider manipulating by her/himself. For the segments' addition I can summarize the following:

\begin{tabular}{|l|l|}
\hline $\begin{array}{l}\text { Process A-(direct) transformations } \\
\text { on segments-objects }\end{array}$ & $\begin{array}{l}\text { Process B- (indirect) } \\
\text { transformations on segments } \\
\text {-objects }\end{array}$ \\
\hline $\begin{array}{l}\text { Transformation of the dynamic } \\
\text { segments, results in the } \\
\text { transformations of the segments' } \\
\text { distances and the segments' sum. }\end{array}$ & $\begin{array}{l}\text { Transformation of the dynamic } \\
\text { parameters (parents' objects), } \\
\text { results in the transformations of } \\
\text { the segments' distances and the } \\
\text { segments' sum }\end{array}$ \\
\hline \multicolumn{1}{|c|}{ Analysis of transformations } & \multicolumn{1}{|c|}{ Analysis of transformations } \\
\hline $\begin{array}{l}\text { Transformation of the geometrical } \\
\text { objects results to the } \\
\text { transformations of the algebraic } \\
\text { objects and finally the } \\
\text { transformation of the mixed-hybrid } \\
\text { object. }\end{array}$ & $\begin{array}{l}\text { Transformation of the algebraic } \\
\text { entities, results to the } \\
\text { objects and finally the } \\
\text { transformation of the mixed-hybrid } \\
\text { object. }\end{array}$
\end{tabular}

Table 2: The addition and the sum of two segments in a DGS

In general, a concrete parameter defines the particular member of a function family. As the parameter changes the transformations of segments, as well as the transformations of the diagram's synthesis appear on screen.

In the examples mentioned above the segments $\mathrm{AB}=\mathrm{a}, \mathrm{CD}=\mathrm{b}$ under the transformation $\mathrm{T}$ of the dynamic parameters will become the corresponding elements $\mathrm{T}(\mathrm{a}), \mathrm{T}(\mathrm{b})$. The dynamic objects created using parameters in the current study play a pivotal role in fostering/scaffolding understanding. Are these objects dynamic, or have we created "static" objects in a DGS 
environment? What is their "static" role in a DGS environment? What are the transformations the concrete dynamic diagram and the objects created in this representation perform? Moreover, can we make a "construct" that appears invariant, even if we drag its visible points on screen? Does this diagram have the same properties? In this case, we have created a "different" hybrid diagram.

\section{Dynamic-Hybrid diagrams}

We can construct a rectangle using:

- Segments (tools) and perpendicular or parallel lines (commands) from the Construct menu of the DGS environment;

- Segments (tools) and transformational processes from the Transform menu;

- Parameters to represent its sides and its angles from the Graph menu.

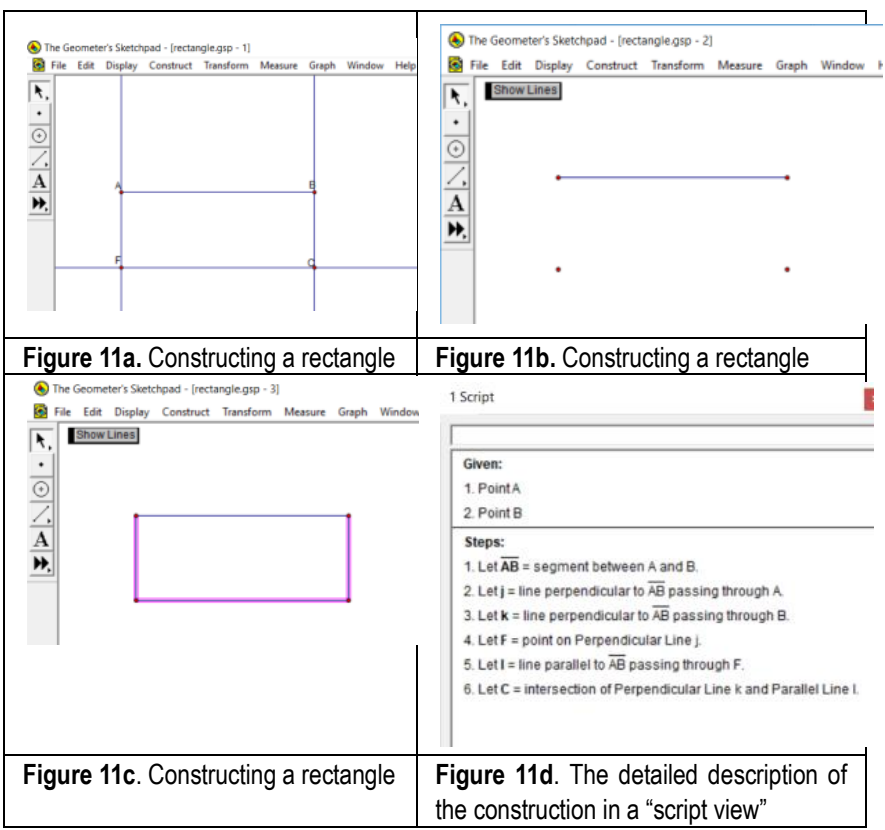

In the images above, we can see a rectangle created in the Geometer's Sketchpad environment; linking pages have been used to allow a user to visualize the sequential steps in its construction. The detailed description of the construction is visible in a "script view", a custom tool I created by selecting all the dynamic objects. As we can see, in the script view, the order of the sequential actions are (Fig. 11d): (a) construction of a segment AB, (b) construction of two perpendicular lines $j, k$ to $\mathrm{AB}$ passing through A and B respectively, (c) construction of a point $\mathrm{F}$ on the perpendicular line, (d) construction of a parallel line 1 to $\mathrm{AB}$ passing through point $\mathrm{F}$, and (e) definition of the intersection between the parallel line $l$ and the perpendicular line $\mathrm{k}$. To keep construction similar to that of a static rectangle, the perpendicular lines (auxiliary lines) have been hidden.

In the second image (Fig. 11b), we can see just three objects on screen: the line $\mathrm{AB}$ and the points F, C. The concrete construction step differentiates the construction in the DGS environment from the construction in a static environment. Point C, for example, is dependent and invariant object. If we drag point $\mathrm{C}$ the dynamic rectangle becomes a static image, which can be moved without alteration on screen. The custom tool demonstrates the hybrid object $\mathrm{C}$ as an intersection of points, as well as the degrees of freedom that these points have. Point A has two degrees of freedom and point $\mathrm{F}$ has one degree since it can be dragged only on line $\mathrm{j}$. If we delete point $\mathrm{A}$, the whole construction will be deleted. I have created a dynamic diagram which consists of dynamic or hybrid objects and depends on the order in which these objects were created. We have a few free "given or parents" objects for the construction and dependent "children objects". For example: if we drag points A, B, F the dynamic object becomes an active representation and can be modified. If we create the rectangle using parameters and tools, the dynamic object is more complex and consists of additional hybrid objects (Fig.12a, b). Point C and B are two vertices of the rectangle, which cannot be transformed on screen using dragging. We can animate parameters and transform the hybrid diagram into a dynamic diagram. If we animate parameters, we can see the alteration in the rectangle's lengths. Figure $12 \mathrm{~b}$ illustrates a parametrical rectangle which has been transformed into a square. Monaghan (2000) supports that most students "recognize a rectangle where the vertical width is greater than the horizontal length [...]. This perception, of course, is commonly held but is mathematically inaccurate as it ignores the square as a special case of rectangle" (Monaghan, 2000, pp. 186-187).

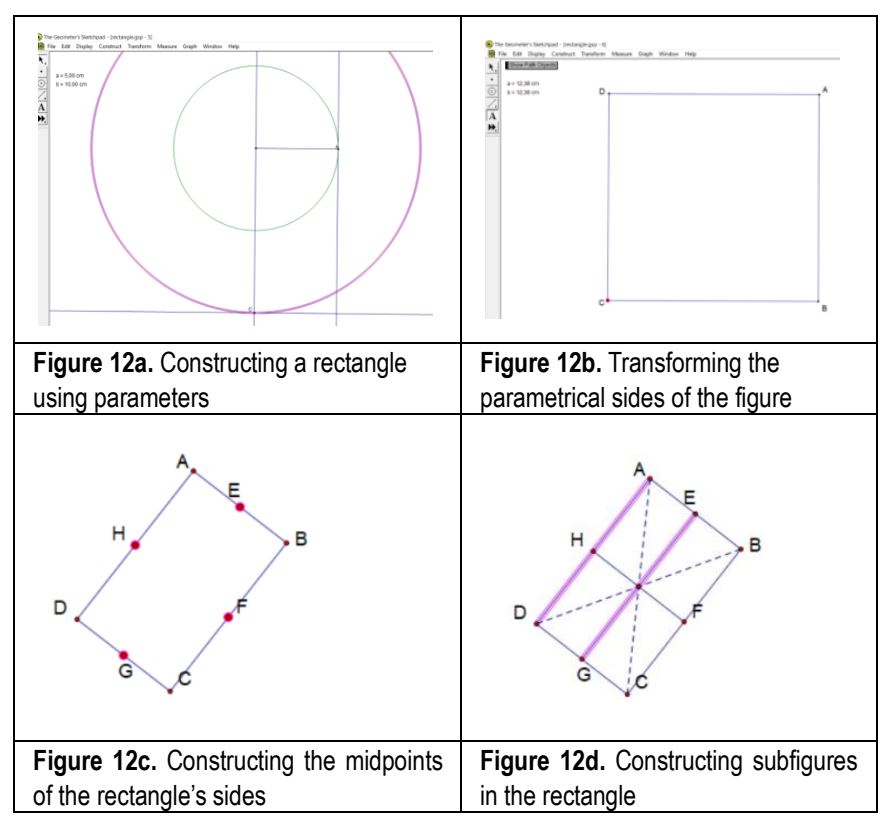

The modification of the figural part of the rectangle is in correlation with the transformation of the parameters in order to become equal. This action on the algebraic objects can help the students to grasp the meaning of square as a rectangle. For this, a student has the opportunity to visualize a combination of transformations (e.g., transformation of sides' lengths, animation of sides' parameters etc.). It is definitely a dynamic diagram, but if 
we do not animate the parameters it is a static hybrid diagram because, it has been intrinsically defined with concrete length of sides that cannot be modified by dragging. The object is a hybrid object due to the dependence of the reported above point from its parent's objects.

If we construct the midpoints of the rectangle's sides (Fig. 12d, 13), they divide the whole figure into subfigures (e.g. sub-rectangles, right triangles, isosceles triangles, or trapeziums), indicating the rectangles' lines of symmetry (meaning the lines which the construction of the symmetrical point for any point of the figure leave the figure unmodified or the imaginary line or axis that passes through the centre of the object and divides it into identical halves). The students can conceive the objects both operationally, as they perform actions on them (physically or mentally), and structurally with concrete properties (for example, the line of symmetry EG is perpendicular to $\mathrm{AB}$, $\mathrm{CD}$, parallel to the sides $\mathrm{AD}, \mathrm{BC}$ and passes from the intersection point of the diagonals). Many objects can be perceived if we implement permanent annotation (e.g., coloring the figures) and transform the figure using dragging (Fig. 13).

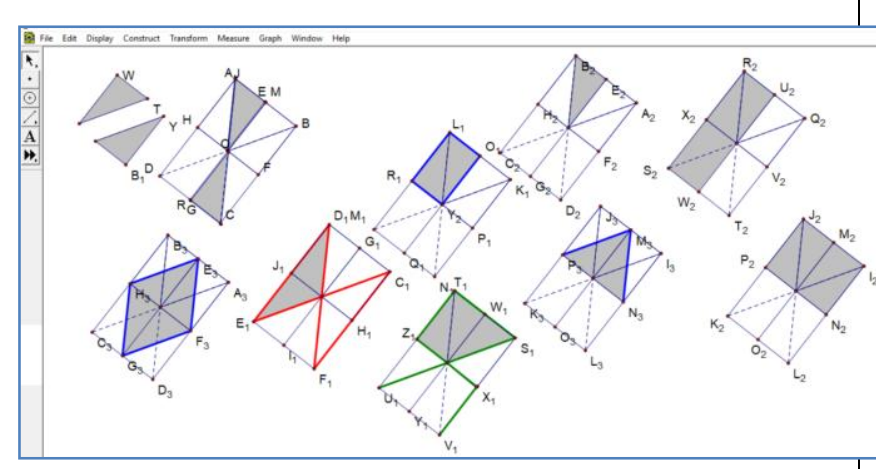

Figure 13. Constructing subfigures in the rectangle, using permanent annotation

For example, from a diagram with congruent triangles which occurred from a rotation through 90 degrees (Fig. $15 \mathrm{a}, \mathrm{b}, \mathrm{c}, \mathrm{d})$, the students can develop two subgoals (e.g., Patsiomitou, 2008b, c, 2010, 2012a): firstly, proving that the sides are equal and, secondly--stemming from the segment's perpendicularity, proving that the sides are parallel. This is to say they have developed a conceptual object: the same objects act as parallel lines and as equal sides.

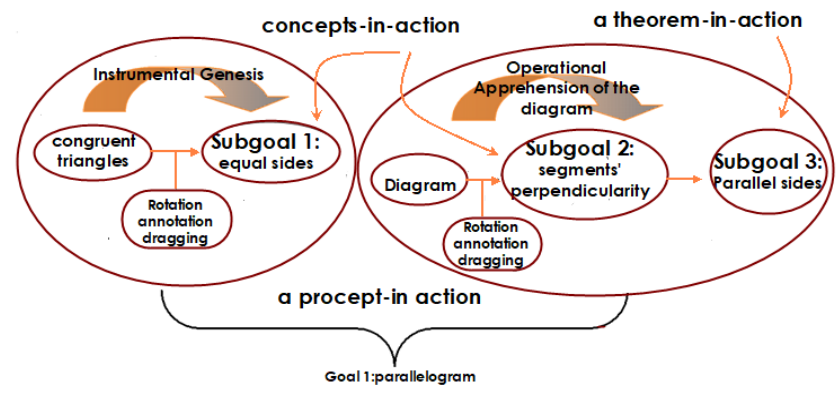

Figure 14. Developing subgoals and goals

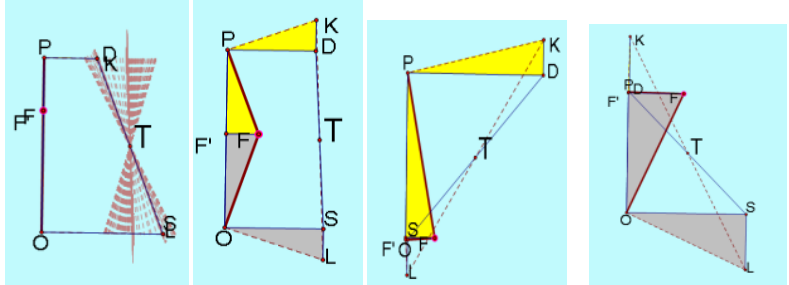

Figure 15a, b, c, d. Dynamic linking active diagrams (Patsiomitou, 2008c, 2010, p.12)

Using actions on objects and performing processes, they achieved their goal of developed the concept-in-action of a parallelogram (Fig. 14). Another example of a students' verbal inductive formulation during a previous study (Patsiomitou, 2008b, 2010, p.12) is the following.

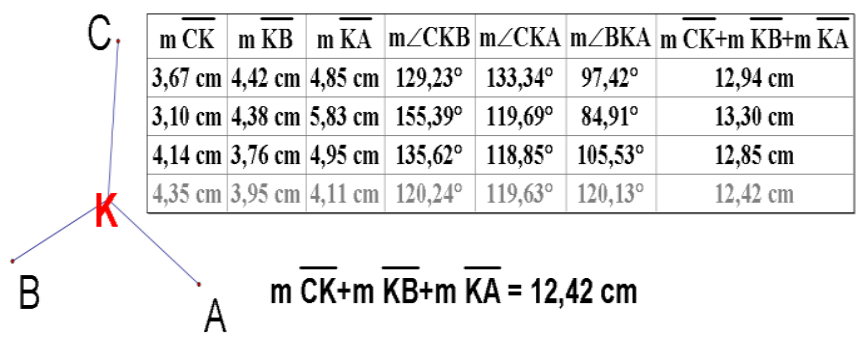

Figure 16. Dynamic linking active diagrams (Patsiomitou, 2008c, 2010, p.12)

The students investigate the modifications made to the calculations of the segments to identify the different positions of point $\mathrm{K}$. Changing the position of point $\mathrm{K}$ by dragging it is dynamically linked to the changes/ modifications in the resultant angles in the table and the upcoming modification to the sum of the segments. This process encourages students to observe that the minimal sum is observed when the angles are at $120^{\circ}$ (Fig. 16). The students are usually led to draw rough conclusions regarding the position of the point under investigation; for instance, that it is the circumcentre of the triangle ABC. The construction of the circumcentre and the measurements reveal cognitive conflicts in the students. The addition of a new line in the table for new measurements every time point $\mathrm{K}$ is dragged can lead students to posit inductive formulations which converge on the angles between the segments being 120 degrees. During this process, we have a reversible (bi-directional) transformation of a) the geometrical into an algebraic model, and b) the algebraic conclusions drawn from comparisons between on-screen dragging on the geometrical representation.

\section{A dynamic iterated procept-in-action}

In the diagram below, I have constructed a golden rectangle using two important procedures (Patsiomitou, 2006b, p. 61, 2008a, in Greek): "creating a custom tool that repeats the ratio 1,61803 (=number $\varphi$ ), and the iteration process that repeats the whole procedure and the measurements and calculations displayed in the table". In this construction, we can view algebraic objects, diagrammatic objects and tabular representations, along with parametrical objects used operationally and 
structurally, and dynamic or hybrid objects. In the tabular representation, we can view the results of measurements and calculations repeated thanks to the iteration process, which generates final for initial objects on a one-to-one basis. According to Patsiomitou (2007) "Through the application of the custom tool the possibility is given to the user to acquire an inductive way of thinking for the finite steps of the construction but the generalisation with regard to the constructional result can be achieved from the process of iteration which inductively renders the construction theoretically to infinity (Patsiomitou, 2005, 2006a, 2009).

This function of the software also constitutes a certain crucial and essential particularity, while the construction with a compass and a ruler as formal tools of static geometry has a beginning and an end. In the software, via the process of iteration we have the potential of the constructions thus becoming more complex being in theory rendered inductively to infinity. The result of the process of iteration is the construction of the tables that repeat the process of initial measurements and calculations in dynamic connection with the shape, thus increasing (or decreasing) the level of the process of iteration while the software adds (or removes) the next level of measurements (or even calculations), whereas in the first column of the table the sequence of the natural numbers is presented. In that way through this operation, the environment of the software promotes the investigation of the sequences. The iteration process by functioning thus has integrated or embodied the meaning of sequence while there is a direct connection between the user's perception and the abstract mathematical meaning. The process of animation can produce the changes in the tabulated measurements (calculations) that allow the user to examine the dynamic process. These changes come as result of the fluctuations in the size of an artefact-fractal which have the possibility of increasing (decreasing) and altering orientation”.

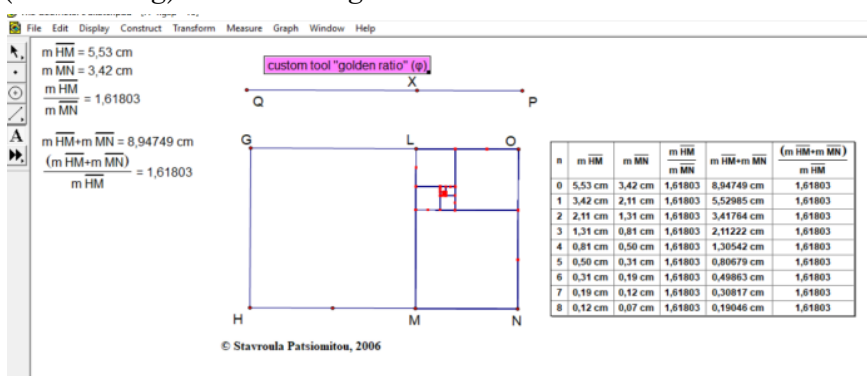

Figure 17a. Creating a golden rectangle using a custom tool (Patsiomitou, 2006, p. 61 , in Greek) and the iteration process

The dynamic linking of the tabulated measurements from the first two columns results in the plotted points illustrated in Figure 17b. The plotted points are dynamically linked to both the figural object and the tabular representation, but cannot be moved or dragged, and are left unaffected if we drag point G (a DGS object with two degrees of freedom), even if the measurements in the tabular representation are affected. The plotted points are dynamic-hybrid objects (Fig. 17c).

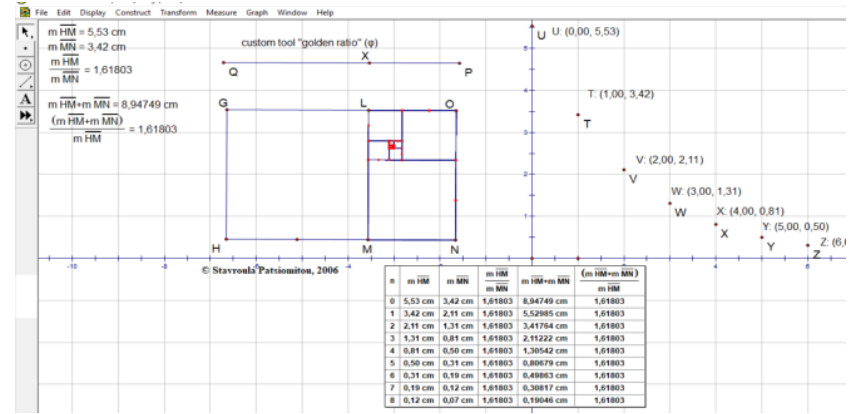

Figure 17b. Dynamic linking of the tabulated measurements with the plotted points

In other words, it is a geometric function which repeats one-to-one transformations on algebraic, geometric and dynamic objects. The concepts-in-action (and theorems-in-action) which occur during the procedure are the results of dynamic elementary procepts-in-action. They are intrinsically dynamic and their impact on students' understanding of the meaning of sequence is crucial (Patsiomitou, 2005, in Greek).

For example, as I mentioned in previous works (e.g., Patsiomitou, 2005, 2007) "The surprise was made by a female-student who, while passively watching and not participating in the duration of the process she comprehended that "as $N$ increases (natural numbers), $E$ (the area) is continuously reduced" a fact which she expressed verbally and repeated it in writing. From this, we may conclude that she momentarily overcame her fear of mathematics, after she had a verbal interaction with the remaining members of the team and was led towards the comprehension of the meaning of limit only by the representations and the reaction towards the computer software".

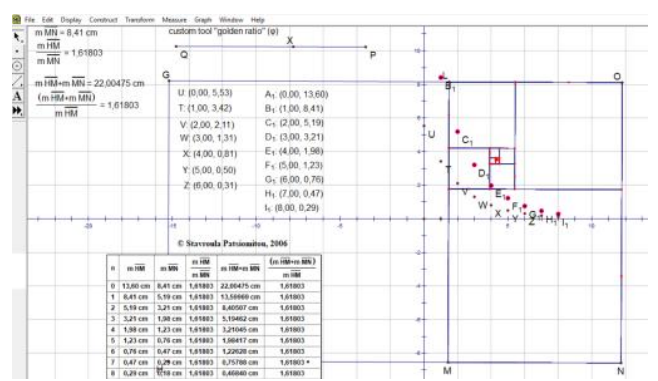

Figure 17c. Dynamic linking of the tabulated measurements with the plotted points

\section{Discussion}

Firstly, I will discuss the different kinds of transformations and transformational results that ensue from implementing dragging on screen.

- Dragging and tracing of a geometric object (for example a point, segment or line)

Dragging a point on screen results in the transformation of its position and the simultaneous appearance of traces on screen tracking the path the point has followed or the tracks that a line passes due to dragging transformations. This action reveals in the determination of a basic property of the diagram that cannot be directly perceived from the diagram in its 
hybrid form, or a property of the diagram that remain stable and unaltered.

\section{- Dragging and measuring (or calculations) the} geometric object.

Dragging a point on screen leads to a change in the measurements of the object that we have chosen to display and in its calculations. In this case, the measurements change, but the calculations may do one of two things: they may remain unchanged, indicating a stability that demonstrates the validity of a theorem or general theoretical approach (a proposal or a confirmed porisma--meaning a conclusion or an inference) or they may change, allowing the user to observe and draw conclusions from empirical results.

- Dragging and animating, or dragging, animating and tracing objects

A point on an object is dragged--for example, the vertex point of a triangle to which a point on one side is connected with motion. The animation of the diagram and the simultaneous dragging allow us to understand a condition which is not defined during the diagram's structuring process. For example, it may make us aware of a theoretical limitation that has not been determined or established before, but which appears on the diagram when it is dragged. This condition leads into an investigation of the validity of a theorem or proposal.

Other complex transformations include: dragging and annotating a dynamic figure, dragging a custom tool to reveal a complex construction and the measurements/calculations of the incorporated objects, dragging an iterated figure and dragging a rotated/translated/or reflected figure (Fig. 15a, b, c, d, 17c).

The diagrams' reconfiguration through the complex synthesis of combinations of transformations can lead to a continuous interaction of discursive, visual and operational apprehension (e.g., Patsiomitou, 2008b, c, 2010, 2011, 2012a, b, 2013, 2014, 2018b). In the words of Dina van Hiele (1984) the diagram goes through a metamorphosis as a result of the manipulations of reconfigurations "followed by a phenomenological analysis and an explicating of its properties: it becomes what we call a [dynamic] geometric symbol" (Dina van Hiele in Fuys et al., 1984, p.221).

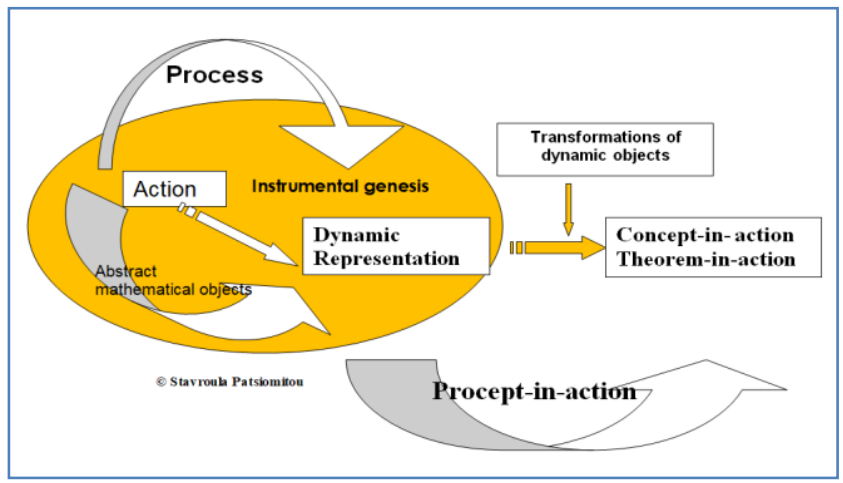

Figure 18. A procept-in-action during instrumental genesis
The synthesis of the transformations results to the construction of instruments and instrumented action schemes which denote the existence of concepts-in-actions and theorems-in-action. The students can manipulate the dynamic diagrams during instrumental genesis. The dynamic section's "metamorphosis" could be considered as a conceptual entity while its use can allow the properties of the dynamic- hybrid diagrams to be analyzed and synthesized back in a conceptual object (Sfard, 1991).

Building on the above, I think there is a continuous process ongoing in students' mind as they create a concept. The meaning of 'procept' is thus dynamic in a DGS environment; adapting its meaning to a 'procept-in-action' for the DGS environment could thus support the appearance of operational invariants during the problem-solving situation and the students' actions on a dynamic object or a dynamic representation/diagram. As a dynamic composition changes in the linking pages, there is a transformation of the (student-) user's verbal formulations due to his/her organized actions on dynamic objects. Consequently, students can develop conceptual transformations during the process of dynamic geometry problem-solving as a means of achieving meaningful and deep learning and/or increasingly conceptual model building (e.g., Greeno, 1983; Mayer, 2000).

\section{References}

Adda, J. (1984) Fight Against Academic Failure in Mathematics.. In Peter Damerow Mervyn E. Dunkley, Bienvenido F. Nebres and Bevan Werry (eds), 'Mathematics for All'. Reports and papers presented in Theme Group I, at the 5th International Congress on Mathematical Education, Adelaide, Paris: UNESCO, Science and Technology Education Document Series, no. 20: pp. 58-61

Balacheff, N. Kaput, J. (1997) Computer-based learning environment in mathematics. Alan Bischop. International Handbook of Mathematics Education, Kluwer Academic publisher, pp.469501, 1997. <hal-01775249>

Chevallard, Y. (1989) Le passage de l'arithmétique à l'algèbre dans l'enseignement des mathématiques au collège Petit $\mathrm{x}, 19,43-72$.

Cerulli, M. (2004): Introducing pupils to algebra as a theory: L'Algebrista as an instrument of semiotic mediation. PhD Thesis, Dipartimento di Matematica, Università degli Studi di Pisa

Coxford, A. F., Usiskin Z. P.(1975). Geometry: A Transformation Approach, Laidlaw Brothers, Publishers.

Cottrill, Jim, Dubinsky, Ed, Nichols, Devilyna, Schwingendorf, Keith, Thomas, Karen \& Vidakovic, Draga (1996). Understanding the limit concept: Beginning with a co-ordinated process schema. Journal of Mathematical Behavior, 15, 167-192.

Davis, R. B. (1983). Complex Mathematical Cognition. In Herbert P. Ginsburg (Ed.) The Development of Mathematical Thinking, (pp. 254-290). Academic Press, New York.

Davis, R. B. (1984). Learning mathematics: The cognitive approach to mathematics education. London: Croom Helm

Davis, G., Tall, D., Thomas, M.(1997) What is the object of the encapsulation of a process? Proceedings of MERGA. Rotarua, New Zealand, July, 1997, vol. 2 , pp. 132-139.

Dienes, Zoltan P. (1960). Building up Mathematics, Hutchinson Educational: London.

Drijvers, P. \& Gravemeijer, K. (2005). Computer Algebra as an Instrument. In Guin, D. et. Al. pp 163-196

Drijvers, P., \& Trouche, L. (2008). From artifacts to instruments: A theoretical framework behind the orchestra metaphor. In G. W. Blume \& M. K. Heid (Eds.), Research on technology and the teaching and learning of 
mathematics: Vol. 2. Cases and perspectives (pp. 363-392). Charlotte, NC: Information Age.

Dubinsky, E. (1986). Teaching mathematical induction I. Journal of Mathematical Behavior, 5(3), 305-317.

Dubinsky, E. \& Lewin, P. (1986). Reflective abstraction and mathematics education. Journal of Mathematical Behavior, 5, 55-92.

Dubinsky, E. (1988). On Helping Students Construct the Concept of Quantification. 12th International Conference Psychology of Mathematics Education. Veszprem. vol. l:255-262.

Dubinsky, E. (1991). Reflective abstraction in advanced mathematical thinking. In D. O. Tall (Ed.), Advanced Mathematical Thinking (pp. 95-123). Dordrecht: Kluwer Academic Publishers

Dubinsky, E. \& McDonald, M. (2001). APOS: A constructivist theory of learning. In D. Holton (Ed.) The Teaching and Learning of Mathematics at University Level: An ICMI Study (pp. 275-282). Dordrecht: Kluwer Academic Publishers

Duval R. (1988). Graphiques et equations: l'articulation de deux registres, in Annales de Didactique et de Sciences Cognitives, 1, 235-255

Duval R. (1993). Registres de représentations sémiotique et fonctionnement cognitif de la pensée. Annales de Didactique et de Sciences Cognitives, ULP, IREM Strasbourg. 5, 37-65.

Duval R. (1995). Geometrical pictures: Kinds of representation and specific Processings. In Exploiting Mental Imagery with Computers in Mathematics Education (R. Suttherland \& J. Mason Eds.) Berlin: Springer pp. 142-157

Duval R. (1999) Representation, vision and visualization: cognitive functions in mathematical thinking. Basic issues for learning. Plenary session Proceedings of the Annual Meeting of the North American Chapter of the International Group for the Psychology of Mathematics Education, Cu-ernavaca, Morelos, México.

Duval, R. (2000) Basic issues for research in mathematics education, In T. Nakahara, M. Koyama (Eds.), Proceedings of the $24^{\text {th }}$ Conference of the International Group for the Psychology of Mathematics Education, (Vol 1, pp. 55-69) Hiroshima: Hiroshima University

Duval, R. (2002). The cognitive analysis of problems of comprehension in the learning of mathematics. Mediterranean Journal for Research in Mathematics Education, 1(2), 1-16.

Duval, R. (2006). A cognitive analysis of problems of comprehension in a learning of mathematics. Educational Studies in Mathematics, 61, 103-131

Fischbein, E. (1993) The theory of figural concepts, Educational Studies in Mathematics, 24(2), 139-162.

Fischbein, E. (1994). The interaction between the formal, the algorithmic, and the intuitive components in a mathematical activity. In R. Biehler, R. W. Scholz, R. Straber, B. Winkelmann (Eds.), Didactics of Mathematics as a Scientific Discipline (pp. 231-245). Dordrecht: Kluwer Academic Publishers. Printed in the Netherlands.

Fuys, D., Geddes, D., \& Tischler, R. (Eds). (1984). English translation of selected writings of Dina van Hiele-Geldof and Pierre M. van Hiele. Brooklyn: Brooklyn College. (ERIC Document Reproduction Service No. ED 287 697).

González G., Herbst P. (2009) Students' conceptions of congruency through the use of dynamic geometry software. International Journal of Computers for Mathematical Learning. 14 (2) 153-182.

Goldin, G., \& Shteingold, N. (2001). Systems of representations and development of mathematical concepts. In A. Cucoco, \& Curcio, $F$ (Ed.). The roles of representation in school mathematics (pp. 1-23). Reston: National Council of Teachers Mathematics.

Gray, E. M., \& Tall D. O. (1991). Duality, Ambiguity and Flexibility in Successful Mathematical Thinking, Proceedings of PME XIII, Assisi Vol. II 72-79

Gray, E. M. \& Tall, D. O. (1994). Duality, Ambiguity and Flexibility: A Proceptual View of Simple Arithmetic. Journal for Research in Mathematics Education, 26 2, 115-141

Greeno, James (1983). Conceptual Entities. In Dedre Gentner, Albert L. Stevens (Eds.), Mental Models, (pp. 227-252). Hillsdale, NJ: Lawrence Erlbaum Associates

Hoffmann, M. H. G. (2004). Learning by Developing Knowledge Networks. Zentralblatt für Didaktik der Mathematik ZDM, 36 (6), 196-205.

Hollebrands, K. F. (2003). High school students' understandings of geometric transformations in the context of a technological environment. Journal of Mathematical Behavior 22 (2003) 55-72.

Hollebrands, K. (2007). The role of a dynamic software program for geometry in the strategies high school mathematics students employ. Journal for Research in Mathematics Education, 38(2), 164-192.
Hollebrands, K., Laborde, C., \& StraBer, R. (2008). Technology and the learning of geometry at the secondary level. Research on Technology and the Teaching and Learning of Mathematics, 1, 155-205.

Hohenwarter, M. (2001). GeoGebra. Online at: http://www.geogebra.org/cms/.

Jackiw, N. (1991) The Geometer's Sketchpad (Computer Software).Berkeley, CA: Key Curriculum Press.

Jackiw, R. \& Finzer, F. (1993). The Geometer's Sketchpad: Programming by Geometry, in A. Cypher (ed.), Watch What I Do: Programming by Demonstration (pp. 293-308). Cambridge, London: The MIT Press.

Janvier, C. (1987) Translation Processes in Mathematics Education. In Janvier C. (Ed.) Problems of Representation in the Teaching and Learning of Mathematics, Hillsdale, New Jersey: Lawrence Erlbaum Associates, 27-32,

Kaput, J. J. (1987). Representation systems and mathematics. In C. Janvier (Ed.), Problems of Representation in the Teaching and Learning of Mathematics (pp. 19-26). New Jersey: Lawrence Erlbaum Associates

Kaput, J. (1991). Notations and representations as mediators of constructive processes. In E. Glasersfeld (Ed.),Radical Constructivism in Mathematics Education (pp. 53-74). Netherlands: Kluwer Academic Publishers.

Kaput, J. (1999). Representations, inscriptions, descriptions and learning: A kaleidoscope of windows. Journal of Mathematical Behavior, 17(2), 256-281.

Laborde, C (2003). Technology used as a tool for mediating knowledge in the teaching of mathematics: the case of Cabri-geometry. Plenary speech delivered at the Asian Technology Conference in Mathematics. Chung Hau University, Taiwan.

Laborde C. (2004). New technologies as a means of observing students' conceptions and making them develop: the specific case of dynamic geometry. ICME 10 - TSG22, Copenhagen, Denmark

Laborde, J-M., Baulac, Y., \& Bellemain, F. (1988) Cabri Géomètre [Software]. Grenoble, France: IMAG-CNRS, Universite Joseph Fourier.

Mayer, R. E. (2002) "Understanding conceptual change: A commentary". In Reconsidering conceptual change: Issues in theory and practice, Edited by: Limon, M. and Mason, L. 101-111. Dordrecht: Kluwer Academic Publisher

Monaghan, F. (2000) What difference does it make? Children views of the difference between some quadrilaterals, Educational Studies in Mathematics, 42 (2), 179-196.

Pape, S., \& Tchoshanov, M. (2001). The role of representation(s) in developing mathematical understanding. Theory into Practice, 40(2), 118-125.

Patsiomitou, S. (2005). Fractals as a context of comprehension of the meanings of the sequence and the limit in a Dynamic Computer Software environment. Master Thesis. Department of Mathematics. National and Kapodistrian University of Athens. (in Greek)

Patsiomitou, S. (2006a): DGS 'custom tools/scripts' as building blocks for the formulation of theorems-in-action, leading to the proving process. Proceedings of the 5th Pan-Hellenic Conference with International Participation "ICT in Education" (HCICTE 2006), pp. 271-278, Thessaloniki, 5-8 October. ISBN 960-88359-3-3 (in Greek). Http://www.etpe.gr/custom/pdf/etpe1102.pdf

Patsiomitou, S. (2006b): Dynamic geometry software as a means of investigating verifying and discovering new relationships of mathematical objects. "EUCLID C": Scientific journal of Hellenic Mathematical Society (65), pp. 55-78 (in Greek)

Patsiomitou, S. (2006c): Transformations on mathematical objects through animation and trace of their dynamic parameters. Proceedings of the 5th Pan-Hellenic Conference with International Participation. Informatics and Education-ETPE, pp. 1070-1073, Thessaloniki, 5-8 October 2006. ISBN 960-88359-3-3. (in Greek) http://www.etpe.gr/custom/pdf/etpe1213.pdf

Patsiomitou, S. (2007). Fractals as a context of comprehension of the meanings of the sequence and the limit in a Dynamic Computer Software environment. Electronic Proceedings of the $8^{\text {th }}$ International Conference on Technology in Mathematics Teaching (ICTMT8) in Hradec Kralove (E. Milkova, P. Prazak, eds.) University of Hradec Kralove, ISBN. 978-80-7041-285-5 (CD-ROM)

Patsiomitou, S. (2008a). The construction of the number $\varphi$ and the Fibonacci sequence using "The Geometer's Sketchpad v4" Dynamic Geometry software. Proceedings of the 1st Pan-Hellenic ICT Educational Conference, "Digital Material to support Primary and Secondary-level teachers' pedagogical work", p.307-315 Naoussa, 9-11 May 2008.(in Greek)

Patsiomitou, S., (2008b). The development of students' geometrical thinking through transformational processes and interaction techniques in a dynamic geometry environment. Issues in Informing Science and Information Technology journal. Vol.5 pp.353-393. Available on line http://iisit.org/lssuesVol5.htm

Patsiomitou, S. (2008c) Linking Visual Active Representations and the van Hiele model of geometrical thinking. In Yang, W-C, Majewski, M., Alwis T. and 
Klairiree, K. (Eds.) "Enhancing Understanding and Constructing Knowledge in Mathematics with Technology". Proceedings of the $13^{\text {th }}$ Asian Conference in Technology in Mathematics. pp 163-178. Available on line http://atcm.mathandtech.org/EP2008/pages/regular.htm

Patsiomitou, S. (2008d) Custom tools and the iteration process as the referent point for the construction of meanings in a DGS environment. In Yang, W-C, Majewski, M., Alwis T. and Klairiree, K. (Eds.) Proceedings of the $13^{\text {th }}$ Asian Conference in Technology in Mathematics. pp. 179-192.Available on line http://atcm.mathandtech.org/EP2008/pages/regular.html

Patsiomitou, S. (2008e) Do geometrical constructions affect students algebraic expressions? In Yang, W-C, Majewski, M., Alwis T. and Klairiree, K. (Eds.) Proceedings of the $13^{\text {th }}$ Asian Conference in Technology in Mathematics. pp 193-202. ISBN 978-0-9821164-1-8. Bangkok, Thailand: Suan Shunanda Rajabhat University.

Patsiomitou, S. (2009a) The Impact of Structural Algebraic Units on Students' Algebraic Thinking in a DGS Environment. Electronic Journal of Mathematics and Technology (eJMT), 3(3), 243-260. ISSN 1933-2823

Patsiomitou, S. (2009b) Learning Mathematics with The Geometer's Sketchpad v4. Klidarithmos Publications. Volume B. ISBN: 978-960-461-309-0.

Patsiomitou, S. (2010). Building LVAR (Linking Visual Active Representations) modes in a DGS environment at the Electronic Journal of Mathematics and Technology (eJMT), pp. 1-25, Issue 1, Vol. 4, February, 2010, ISSN1933-2823.

Patsiomitou, S. (2011) Theoretical dragging: A non-linguistic warrant leading to dynamic propositions. In Ubuz, B (Ed.). Proceedings of the 35th Conference of the International Group for the Psychology of Mathematics Education, Vol. 3, pp. 361-368. Ankara, Turkey: PME. ISBN 978-975-429-297-8

Patsiomitou, S. (2012a). The development of students' geometrical thinking through transformational processes and interaction techniques in a dynamic geometry environment. $\mathrm{PhD}$ thesis. University of loannina (December 2012).https://www.didaktorika.gr/eadd/handle/10442/35816

Patsiomitou, S. (2012b) A Linking Visual Active Representation DHLP for student's cognitive development. Global Journal of Computer Science and Technology, Vol. 12 Issue 6, March 2012. pp. 53-81. ISSN 9754350. Available at: http://computerresearch.org/index.php/computer/article/view/479/479

Patsiomitou, S. (2013) Students learning paths as 'dynamic encephalographs' of their cognitive development". International journal of computers \& technology [Online], 4(3) pp.802-806 (18 April 2013) https://doi.org/10.24297/ijct.v4i3.4207

Patsiomitou, S. (2014). Student's Learning Progression Through Instrumental Decoding of Mathematical Ideas. Global Journal of Computer Science and Technology, Vol. 14 Issue 1,pp. 1-42. Online ISSN: 0975-4172. http://computerresearch.org/index.php/computer/article/view/41/41

Patsiomitou, S. (2018a). A dynamic active learning trajectory for the construction of number pi $(\pi)$ : transforming mathematics education. International Journal of Education and Research. 6 (8) pp. 225-248.

Patsiomitou, S. (2018b). An 'alive' DGS tool for students' cognitive development. International Journal of Progressive Sciences and Technologies (IJPSAT) ISSN: 2509-0119. Vol. 11, No. 1. October 2018, pp. 35-54.

Patsiomitou, S. (2019). From Vecten's Theorem to Gamow's problem: building an empirical classification model for sequential instructional problems in geometry. Journal of Education and Practice. 10 (5) pp.1-23. DOI: 10.7176/JEP/10-5-01.

Parzysz, B. (1988). Knowing versus seeing: problems of the plane representation of space geometry figures. Educational Studiesin Mathematics, 19(1), 79-92.

Peirce, C.S. (1894). What is a sign? http://www.cspeirce.com/menu/library/bycsp/bycsp.htm. [obtained 16/08/07]

Peirce, C.S. (1933) Collected Papers. Vols 1 and 2. Cambridge, MA: Harvard University Press.

Peirce, C. (1955). Philosophical writings of Peirce. New York: Dover Publications

Piaget, J. (1952/1977). The origins of intelligence in children (M. Cook, Trans.). New York: International University Press.

Piaget, Jean (1953). The Origin of Intelligence in the Child (Margaret Cook, trans.) London: Routledge \& Kegan Paul.

Piaget, J. (1970). Genetic Epistemology, W. W. Norton, New York.

Piaget, Jean (1972a). The Principles of Genetic Epistemology. London: Routledge $\&$ Kegan Paul.

Piaget, J. (1972b). Intellectual Evolution from Adolescence to Adulthood. Human Development, 15, 1-12. http://dx.doi.org/10.1159/000271225.

Piaget, J. (1985). The equilibration of cognitive structures (T. Brown and K. J. Thampy, trans.), Cambridge MA, Harvard University Press, (originally published in 1975).
Plato (360 B.C.). The Republic

Portnoy, N., Grundmeier, T., Grahama, K. (2006). Students' understanding of mathematical objects in the context of transformational geometry: Implications for constructing and understanding proofs. Journal of Mathematical Behavior 25. pp. 196-207.

Rabardel, P. (1995). Les hommes et les technologies, approche cognitive des instruments contemporains. Paris : Armand Colin.

Sfard, A. (1987). Two conceptions of mathematical notions: Operational and Structural. Proceedings of the 11th Conference of the International Group for the Psychology of Mathematics Education, Montreal, Canada, 162-169.

Sfard, A. (1989). Transition from Operational to Structural Conception: The notion of function revisited. In Proceedings of PME XIII, (pp.151-158), Paris, France.

Sfard, A. (1991). On the Dual Nature of Mathematical Conceptions: Reflections on processes and objects as different sides of the same coin, Educational Studies in Mathematics, 22, 1-36.

Sfard, A. (1992). Operational origins of mathematical objects and the quandary of reification - the case of function. In G. Harel \& E. Dubinsky (Eds.), The Concept of Function: Aspects of Epistemology and Pedagogy, MAA Notes 25 (pp. 59-84). Washington DC: MAA.

Sfard, A. (2000) 'Symbolizing mathematical reality into being, How mathematical discourse and mathematical objects create each other', in P. Cobb, K.E. Yackel and K. McClain (eds.), Symbolizing and Communicating, Perspectives on Mathematical Discourse, Tools, and Instructional Design, Erlbaum, Mahwah, NJ, pp. 37-98.

Sedig, K., \& Sumner, M. (2006). Characterizing interaction with visual mathematical representations. International Journal of Computers for Mathematical Learning, 11, 1-55. New York: Springer.

Stewart , S. (2008) Understanding Linear Algebra Concepts Through the Embodied, Symbolic and Formal Worlds of Mathematical Thinking. A thesis submitted in fulfilment of the requirements for the degree of Doctor of Philosophy of Science in Mathematics Education. The University of Auckland, 28 August, 2008.

Steketee, S., \& Scher, D. (2016). Connecting functions in geometry and algebra. Mathematics teacher, 109(6), February 2016, 448-455

Sträßer, R. Macros and Proofs (2003): Dynamical Geometry Software as an Instrument to Learn Mathematics (vol8) Proceedings of 11th International Conference on Artificial Intelligence in Education, Sydney Australia

Tall, D. O., Thomas, M. O. J., Davis, D., Gray, E., \& Simpson, A. (2000). What is the object of the encapsulation of a process? Journal of Mathematical Behavior, 18(2), 223-241.

Trouche, L. (2004). Managing the complexity of the human/machine interaction in computerized learning environments: Guiding students' command process through instrumental orchestrations. International Journal of Computers for Mathematical Learning 9, 281-307. Kluwer Academic Publishers.

Tchoshanov, M. (2013). Engineering of Learning: Conceptualizing e-Didactics. Moscow: UNESCO IITE

Verillon, P. \& Andreucci, C. (2006). Artefacts and cognitive development: How do psychogenetic theories of intelligence help in understanding the influence of technical environments on the development of thought? In M. J. de Vries \& I. Mottier (Eds.), International handbook of technology education reviewing the past twenty years. Rotterdam: Sense Publisher

Verillon, P. \& Rabardel, P. (1995) Cognition and artefacts: A contribution to the study of thought in relation to instrumented activity. European Journal of Psychology of Education, 10(1), 77-101.

Vergnaud, G. (1987) "Conclusion." In C. Janvier (ed.) Problems of Representation in Mathemutics Learning and Problem Solving, Hillsdale, NJ: Erlbaum.

Vergnaud, G. (1996). Au fond de l'apprentissage, la conceptualisation, In R. Noirfalise, \& M.J. Perrin (Eds.), Actes de l'école d'été de didactique des mathématiques (pp. 174-185). ClermontFerrand: IREM, Université de Clermont-Ferrand II.

Vergnaud, G. (1998). A Comprehensive Theory of Representation for Mathematics Education. Journal of Mathematics Behavior, 17(2), 167-181.

Webpage [1]:

https://www.itd.cnr.it/telma/docs/Rep_Del_Draft3.pd 